\title{
Digitaler Druck mit keramischen Lacksystemen
}

\begin{abstract}
Parallel zur Serienfertigung bietet Irlbacher, eine familiengeführte Unternehmensgruppe aus der Oberpfalz, mit keramischem Digitaldruck auf Glas eine Möglichkeit, Einzelstücke und Kleinstserien gestalterisch aufzuwerten. Hinterleuchtung durch auf das Glas bestückte LEDs, industrietaugliche Touch-Lösungen auf Glas sowie haptische Elemente in der Glasoberfläche für blinde Bedienung eröffnen Entwicklern dabei neue Gestaltungsmöglichkeiten.
\end{abstract}

Kaum ein Werkstoff ist so vielfältig einsetzbar wie Glas. Seine Beständigkeit, seine Ästhetik und seine leichte Formbarkeit haben dafür gesorgt, dass anspruchsvolle Touch-Bediensysteme auf Glas heute viele Produkte veredeln - vom Tablet-PC bis zur Industriesteuerung. Sehr wichtig sind dabei neben der Funktionalisierung: Logos in leuchtenden Farben, satte Hintergründe, IR-durchlässige, unsichtbare Fenster für Fernbedienungen und Kommunikationsschnittstellen (Bild 1).

Das Unternehmen Irlbacher setzt im Digitaldruck die gleichen Langzeit-UVbeständigen anorganischen, keramischen Farben ein, wie im Siebdruck bei seinen Serienprodukten. Diese Farben bestehen aus Glasfritten (Glaspulver), Pigmenten, Metalloxiden sowie organischen Lösungsmitteln. Letztere verdampfen bereits in der Vortrocknung bei rund $200^{\circ} \mathrm{C}$. Anschließend wird das verbleibende Material bei über $650^{\circ} \mathrm{C}$ irrever-

\section{Das Unternehmen}

Irlbacher Blickpunkt Glas ist eine weltweit tätige, familiengeführte Unternehmensgruppe der Spezialglas-Technologie mit Sitz in der Oberpfalz. Seit 85 Jahren wird dort Glas verarbeitet. Herstellern von Geräten, Maschinen und Benutzeroberflächen bietet Irlbacher skalierbare Technologie-Plattformen. Beispiele sind hermetisch geschlossene Gehäusefronten, auf denen dennoch Leuchtelemente, Drehund Schieberegler oder Schalter mit haptischer Rückmeldung aufgebracht werden können.

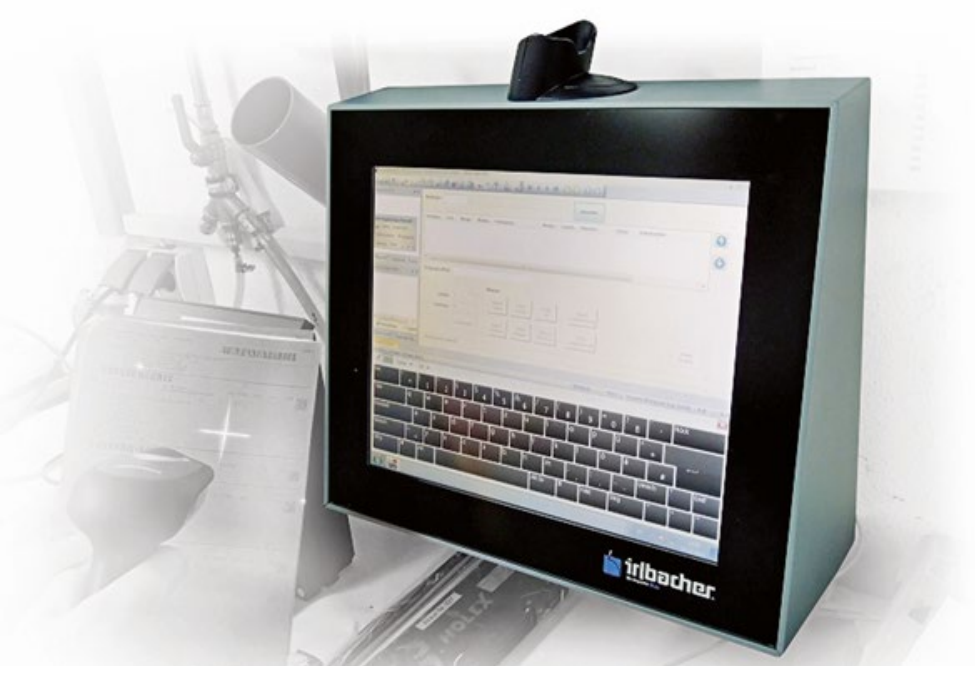

Bild 1 Keramischer Digitaldruck ermöglicht Touch-Funktionsmuster mit den gleichen optischen und technischen Eigenschaften der Serie. Das Beispiel auf dem Bild ist für raue industrielle Umgebung ausgelegt. Die Bedienfläche ist vollflächig verklebt und resistent gegen das Eindringen von Wasser und Fremdkörpern. (৫ Irlbacher)

sibel mit dem Glasträger verschmolzen und gleichzeitig das Glassubstrat zum teilvorgespannten Glas (TVG, bis 2,5 mm Materialstärke) oder zum Einscheiben-Sicherheitsglas (ESG, ab 3 mm Materialstärke) veredelt.

Falls technisch erforderlich, können auch organische Farben digital gedruckt werden. Diese enthalten Polymer-Vorstufen anstatt der Glasfritten. Ausgehärtet werden diese Lacksysteme durch eine Kombination physikalischer und chemischer Verfahren: mit einer Trocknung und anschließenden Polymerisation, ausgelöst durch Wärme oder UVBestrahlung. Dabei entsteht eine Haftverbindung zwischen Farbe und Glas, die jedoch unter bestimmten Bedingungen reversibel ist, die Schichten können delaminieren.
Keramische Lacksysteme sind hier vorteilhaft, weil sie nicht delaminieren können, und bis $300^{\circ} \mathrm{C}$ statt nur bis $120^{\circ} \mathrm{C}$ temperaturstabil sind. Außerdem sind sie zehnfach resistenter gegen Verkratzen und UVbeständig. Da keramische Farben dauerhaft mit dem Trägerglas verschmelzen, lassen sich keramisch bedruckte Glasflächen zudem problemlos verkleben. Alle Siebdruck-Farbsysteme des Unternehmens erfüllen zudem die Anforderungen der EGVerordnung 1907/2006 (REACH) sowie der EU-Richtlinie 2011/65 (RoHS).

Kontakt: Irlbacher Blickpunkt Glas GmbH, Schönsee, www.irlbacher.com/home.html 